\title{
Exploiting the Imidazolium Effect in Base-free Ammonium Enolate Generation: Synthetic and Mechanistic Studies
}

\author{
Claire M. Young, Daniel G. Stark, Thomas H. West, James E. Taylor and Andrew D. Smith(s) ${ }^{*[a]}$
}

\begin{abstract}
N$-Acyl imidazoles and catalytic isothiourea hydrochloride salts function as ammonium enolate precursors in the absence of base. Enantioselective Michael addition-cyclization reactions using different $\alpha, \beta$-unsaturated Michael acceptors have been performed to form dihydropyranones and dihydropyridinones with high stereoselectivity. Detailed mechanistic studies using RPKA have revealed the importance of the "imidazolium" effect in ammonium enolate formation and have highlighted key differences with traditional base-mediated processes.
\end{abstract}

Ammonium enolates generated from tertiary amine-based Lewis base catalysts are versatile intermediates that can be utilized in a range of stereoselective processes. ${ }^{[1]}$ Traditionally accessed directly through nucleophilic attack of tertiary amine catalysts onto ketenes, ${ }^{[1 c]}$ the practical challenges associated with ketene preparation and their use has prompted a number of alternative ammonium enolate precursors to be developed (Scheme 1a). An early approach generated ketenes in situ from the corresponding acid chloride using an organic base. ${ }^{[2]}$ Alternatively, homoanhydrides ${ }^{[3]}$ and electron-deficient phenolate esters $^{[4]}$ can undergo direct nucleophilic addition by suitable Lewis base catalysts to form acyl ammonium intermediates that can be deprotonated under basic conditions to form the required ammonium enolate. Carboxylic acids can also be used as ammonium enolate precursors, but require stoichiometric in situ functionalization into either mixed anhydrides or activated esters prior to the addition of the Lewis base catalyst. ${ }^{[5]}$ All of these procedures typically use an excess of reagents and organic bases, and generate by-products that can be difficult to chromatographically separate from the desired products.

In this manuscript, the development of a new, mild method of catalytically generating ammonium enolates from bench-stable $\mathrm{N}$-acyl imidazole precursors that avoids the use of stoichiometric additives and external base, and instead uses isothiourea hydrochloride salts as catalysts, is reported. Key to the process developed is the exploitation of the reactivity underpinning the "imidazolium effect" - the recognized rate enhancement for acylations using $\mathrm{N}$-acyl imidazoliums compared with $\mathrm{N}$-acyl imidazoles (Scheme 1b). ${ }^{[6]}$ For example, Batey has developed $N$-methyl- $N$ '-carbamoyl imidazolium salts as efficient carbamoyl transfer agents, ${ }^{[7]}$ while Gilday used $N$-acyl imidazoles and stoichiometric imidazole hydrochloride for the challenging acylation of anilines. ${ }^{[8]}$ Sarpong

[a] C. M. Young, D. G. Stark, T. H. West, Dr J. E. Taylor, Prof. A. D. Smith

EaStCHEM, School of Chemistry, University of St Andrews, North Haugh, St Andrews, Fife, KY16 9ST (UK)

E-mail: ads10@st-andrews.ac.uk

Homepage: http://ch-www.st-andrews.ac.uk/staff/ads/group/

Supporting information for this article is given via a link at the end of the document

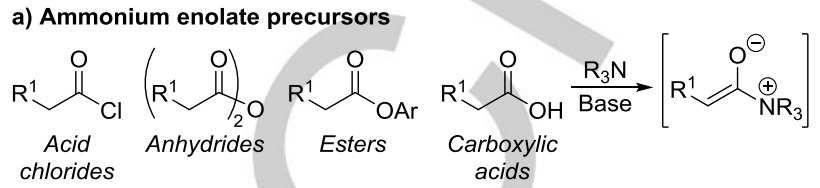

b) "Imidazolium effect": Increased rate of acylation of imidazolium salts

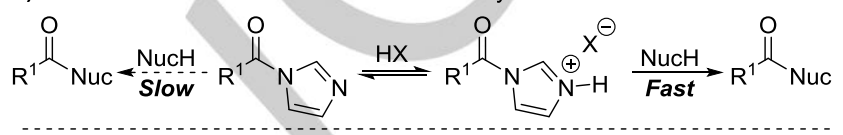
c) This work: Base-free ammonium enolate formation using acyl imidazoles

$$
\text { Base-free enolate formation Mechanistic study Up to 95:5 dr, 99:1 er }
$$

Scheme 1. Ammonium enolate precursors at carboxylic acid oxidation level has reported the dual Brønsted acid and Lewis base activation of $\mathrm{N}$-acyl imidazoles using stoichiometric pyridinium salts for the acylation of alcohols and amines as well as for the esterification of carboxylic acids. ${ }^{[9]}$ Although powerful, to date, this "imidazolium effect" has not been exploited in either a catalytic fashion or for the generation of ammonium enolate intermediates. ${ }^{[10]}$ Furthermore, the expected imidazole byproduct is both non-toxic and water soluble and should be readily removed from reaction mixtures.

To the best of our knowledge, $\mathrm{N}$-acyl imidazoles have not been investigated as ammonium enolate precursors. However, Scheidt and co-workers have previously used $\mathrm{N}$-acyl imidazoles as azolium enolate precursors under basic reaction conditions using $\mathrm{N}$-heterocyclic carbene catalysis to form dihydroquinolones and dihydrocoumarines with good enantioselectivity. ${ }^{[1-12]}$ The protocol developed herein represents a new paradigm in ammonium enolate generation without the addition of external base (Scheme 1c). ${ }^{[13]} A$ range of enantioselective Michael addition-cyclization processes with $\alpha, \beta$ unsaturated enones and ketimines to form substituted dihydropyranones and dihydropyridinones have been explored. Furthermore, a detailed mechanistic investigation has revealed key differences between this new process and analogous reactions using carboxylic acids under basic conditions.

Investigations began with the Michael addition-lactonization reaction between $\mathrm{N}$-phenacyl imidazole 1 (readily prepared from phenylacetic acid and CDI) and trifluoromethylenone 2 (Table 1). ${ }^{[14]}$ Encouragingly, the reaction using (-)-tetramisole (TM) hydrochloride $3(20 \mathrm{~mol} \%)$ in $\mathrm{CH}_{2} \mathrm{Cl}_{2}$ at $\mathrm{rt}$ led to formation of dihydropyranone 4 in 84:16 dr and promising 76:24 er for the major anti-diastereoisomer, albeit in only $18 \%$ yield (Table 1, entry 1). Notably, the same reaction performed in the presence of $i$ - $\mathrm{Pr}_{2} \mathrm{NEt}(2.5 \mathrm{eq})$ also gave 4 , but as a racemate (Table 1 , entry 2), consistent with the addition of external base being detrimental to the enantioselectivity of the process. ${ }^{[15]}$ Changing 
Table 1. Reaction optimization ${ }^{[a]}$

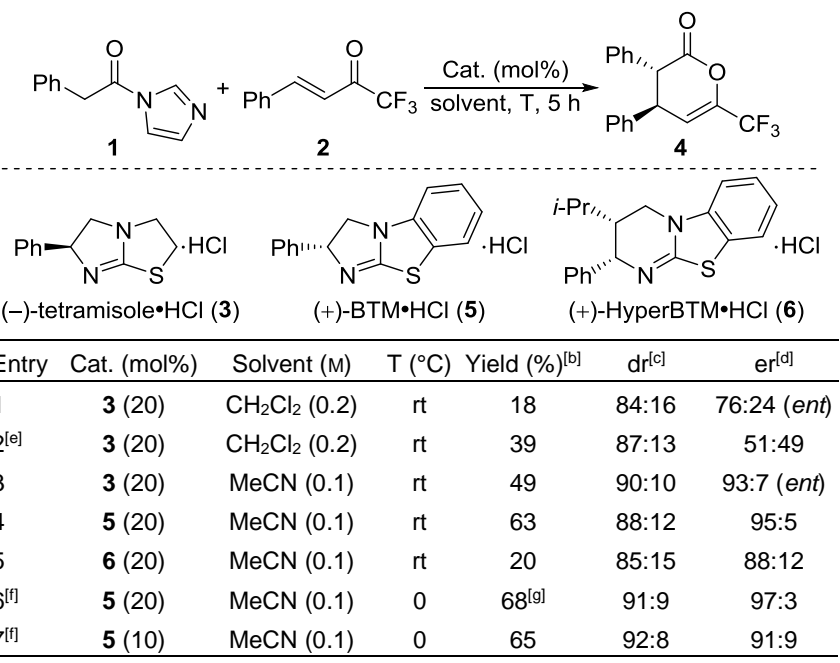

[a] Reactions performed on a $0.1 \mathrm{mmol}$ scale. [b] Determined by ${ }^{1} \mathrm{H}$ NMR using 1,4-dinitrobenzene as internal standard. [c] Determined by ${ }^{1} \mathrm{H}$ NMR spectroscopic analysis of the crude material. [d] Determined by HPLC analysis. [e] Reaction with $i-\mathrm{Pr}_{2} \mathrm{NEt}$ (2.5 eq). [f] Reaction using 1.5 eq 1 for 16 h. [g] Isolated yield.

the solvent to $\mathrm{MeCN}$ led to an improvement in both reactivity and enantioselectivity (Table 1, entry 3 ). A screen of alternative isothiourea catalysts identified (+)-benzotetramisole (BTM) hydrochloride 5 as the most effective, leading to higher yields and improved stereoselectivity (Table 1 , entries 4 and 5 ). Decreasing the reaction temperature to $0{ }^{\circ} \mathrm{C}$ and using $1.5 \mathrm{eq} 1$ led to the isolation of anti-4 in 68\% yield with excellent $91: 9 \mathrm{dr}$ and 97:3 er (Table 1, entry 6). ${ }^{[16]}$ Successive aqueous acid-base work-up allowed imidazole removal and catalyst recovery $(88 \%$ yield). Reducing the catalyst loading to $10 \mathrm{~mol} \%$ led to slightly reduced conversion and enantioselectivity (Table 1, entry 7 ).

The scope of this process was assessed through variation of the $\mathrm{N}$-acyl imidazole (Table 2). Aryl groups bearing electrondonating substituents were tolerated, forming antidihydropyranones 7 and 8 with high enantioselectivity, although a reduction in yield was observed (Table 2, entries 1-2). The presence of electron-withdrawing and halogen aryl substituents (10 and 11) gave comparable results with shorter reaction times, Table 2. Variation of the $\mathrm{N}$-acyl imidazole with trifluoromethylenone 2

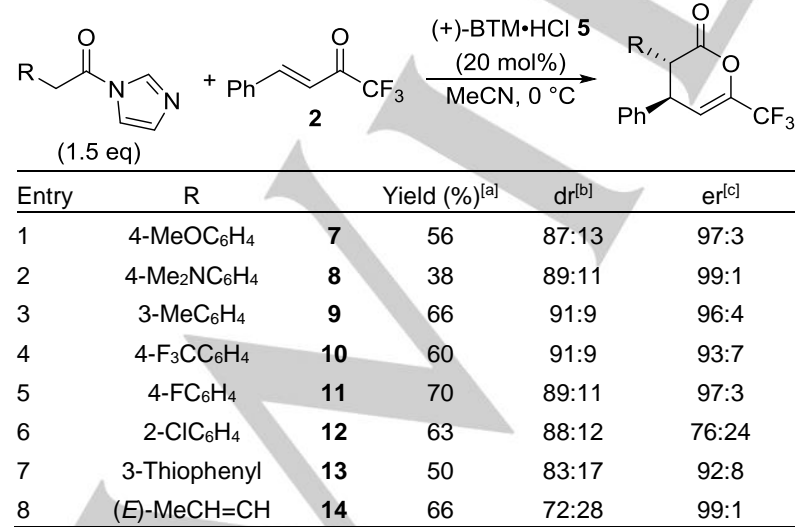

[a] Isolated yields as a mixture of diastereoisomers. [b] Determined by ${ }^{1} \mathrm{H}$ NMR analysis of the crude material. [c] Determined by HPLC analysis. although the presence of an 0 -chloro substituent led to reduced enantioselectivity for anti-12 (Table 2, entries 4-6). Heteroaromatic and alkenyl substituents were also successfully incorporated within 13 and 14, although the latter was obtained with reduced diastereocontrol (Table 2, entries 7 and 8).

To assess whether the protocol was applicable across a range of Michael acceptors, the reaction between $\mathrm{N}$-phenacyl imidazole 1 and $\alpha, \beta$-unsaturated $\gamma$-ketimine ester $\mathbf{1 5}$ to form dihydropyridinone 16 was studied. (-)-TM. HCl 3 (20 mol\%) was the optimal catalyst, with the addition of acetic acid (1.1 eq) necessary to obtain product 16 in high yield, ${ }^{[17]}$ giving 16 in $67 \%$ yield with excellent 92:8 dr and 94:6 er (Table 3, entry 1). ${ }^{[18]}$ The reactions of $\alpha, \beta$-unsaturated $\gamma$-ketimine ester 15 with various $N$ acyl imidazoles displayed similar trends to those observed with trifluoromethylenone 2 . The presence of electron-rich aryl substituents generally led to lower yield, but high enantioselectivity (17-19) whereas dihydropyridinone 20 containing an electron-deficient aryl ring gave decreased enantiocontrol (Table 3, entries 2-5). Notably, o-chloro substitution within 22 gave high stereocontrol (Table 3, entry 7 ).

Table 3. Variation of the $\mathrm{N}$-acyl imidazole with ketimine 15
$(-)-\mathrm{TM} \cdot \mathrm{HCl}$ 3
$(20 \mathrm{~mol} \%)$

[a] Isolated yields as a mixture of diastereoisomers. [b] Determined by ${ }^{1} \mathrm{H}$ NMR analysis of the crude material. [c] Determined by HPLC analysis.

Finally, the use of $\alpha, \beta$-unsaturated saccharin derivatives as Michael acceptors was investigated, with (+)-BTM. HCl 5 (10 mol\%) in EtOAc at rt proving optimal, forming fused dihydropyridinone 23 in 84\% yield with 89:11 dr and 93:7 er (Table 4, entry 1). ${ }^{[17,19]}$ The reaction scope was further assessed through variation of both the $\mathrm{N}$-acyl imidazole and $\alpha, \beta$ unsaturated saccharin. Electron-rich and electron-deficient aryl substituents within the $\mathrm{N}$-acyl imidazole were tolerated, forming 24 and 25 with good yields and high stereoselectivity (Table 4, entries 2 and 3). Alkenyl substitution led to a reduction in yield and diastereoselectivity for 26, although enantioselectivity remained high (Table 4, entry 4). A range of electron-rich, electron-poor and halogen-substituted aryl rings as well as a heteroaryl substituent was tolerated within the saccharin component, forming dihydropyridinones 27-30 in high yield with good stereocontrol in all cases (Table 4, entries 5-8).

Having assessed the reaction scope, the role of the "imidazolium effect" in $\mathrm{N}$-acyl ammonium formation, as well as the mechanism and reaction kinetics of this process was investigated. The importance of using the isothiourea hydrochloride salt was probed by studying the initial equilibrium 
Table 4. Reaction scope with $\alpha, \beta$-unsaturated saccharin derivatives

\begin{tabular}{|c|c|c|c|c|c|c|}
\hline Entry & $\mathrm{R}$ & $\mathrm{Ar}$ & & Yield (\%) ${ }^{[a]}$ & $\mathrm{dr}^{[\mathrm{b}]}$ & $e^{[c]}$ \\
\hline 1 & $\mathrm{Ph}$ & $\mathrm{Ph}$ & 23 & 84 & $89: 11$ & $93: 7$ \\
\hline 2 & 3- $\mathrm{MeC}_{6} \mathrm{H}_{4}$ & $\mathrm{Ph}$ & 24 & 66 & $88: 12$ & $93: 7$ \\
\hline 3 & $4-\mathrm{F}_{3} \mathrm{CC}_{6} \mathrm{H}_{4}$ & $\mathrm{Ph}$ & 25 & 83 & $88: 12$ & $90: 10$ \\
\hline 4 & $(E)-\mathrm{MeCH}=\mathrm{CH}$ & $\mathrm{Ph}$ & 26 & 42 & $76: 24$ & $91: 9$ \\
\hline 5 & $\mathrm{Ph}$ & $4-\mathrm{MeOC}_{6} \mathrm{H}_{4}$ & 27 & 80 & $88: 12$ & $93: 7$ \\
\hline 6 & $\mathrm{Ph}$ & $4-\mathrm{F}_{3} \mathrm{CC}_{6} \mathrm{H}_{4}$ & 28 & 92 & $88: 12$ & $94: 6$ \\
\hline 7 & $\mathrm{Ph}$ & $4-\mathrm{BrC}_{6} \mathrm{H}_{4}$ & 29 & 98 & $94: 6$ & $91: 9$ \\
\hline 8 & $\mathrm{Ph}$ & 3-Thiophenyl & 30 & 82 & $86: 14$ & $92: 8$ \\
\hline
\end{tabular}

[a] Isolated yields as a mixture of diastereoisomers. [b] Determined by ${ }^{1} \mathrm{H}$ NMR analysis of the crude material. [c] Determined by HPLC analysis.

between the catalyst and $N$-phenacyl imidazole 1. An equimolar mixture of 1 and free-base (+)-BTM 31 in $\mathrm{CD}_{3} \mathrm{CN}$ showed no evidence of catalyst acylation by ${ }^{1} \mathrm{H}$ NMR. In contrast, an equivalent mixture of $(+)-\mathrm{BTM} \cdot \mathrm{HCl} 5$ and 1 led to rapid equilibration with the corresponding $\mathrm{N}$-acyl ammonium 32 and free imidazole 33, with $K_{\text {exp }}=0.59$ (Scheme 2a). ${ }^{[20]}$ The position of this equilibrium is not the only contributing factor to reactivity, as using $\mathrm{N}$-acyl triazoles instead of $\mathrm{N}$-acyl imidazoles gave higher equilibrium constants but displayed lower overall reactivity in reactions to form $4{ }^{[21]}$ Furthermore, a 1:1 mixture of $\mathrm{N}$-acyl ammonium $\mathbf{3 2}$ and $\mathrm{N}$-acyl imidazole $\mathbf{3 4}$ showed significant cross-over after $4 \mathrm{~h}$ (Scheme $2 \mathrm{~b}$ ), adding to the complexity of the initial equilibrium. ${ }^{[22]}$ The nature of the nonparticipating counter-ion was not important for overall reactivity, with a range of $(+)$-BTM.HX salts giving comparable results in the reaction to form $4 .{ }^{[21]}$ Isolated $\mathrm{N}$-acyl ammonium 32 and imidazole 33, or acyl imidazolium ion 36 and (+)-BTM 31 (20 mol\%), are competent precatalysts, reacting with $\mathbf{1}$ and $\mathbf{2}$ to form dihydropyranone 4 in high er (Scheme 2c). A 1:1 mixture of $N$ acyl ammonium 32 and enone 2 did not lead to product formation indicating the presence of either imidazole or $\mathrm{N}$-acyl imidazole is essential for reactivity.

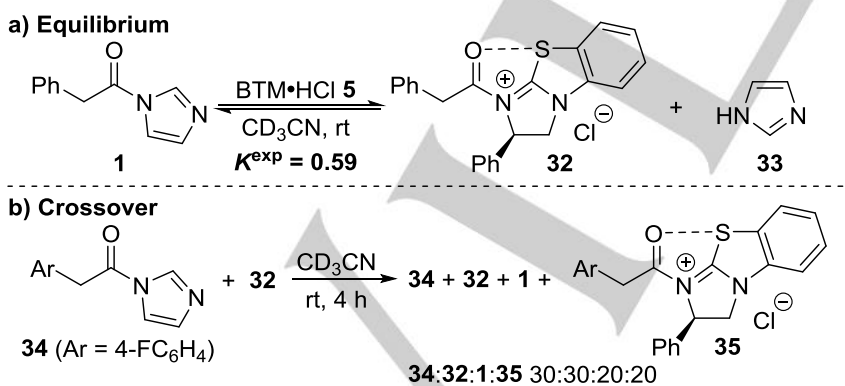

c) Precatalyst Investigation

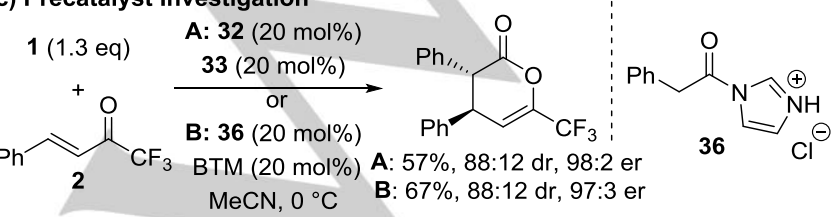

Scheme 2. a) Equilibrium between $\mathrm{N}$-acyl imidazole $\mathbf{1}$ and acyl ammonium 32. b) Crossover experiment. c) Use of alternative precatalysts.
The reaction kinetics were then assessed using the Reaction Progress Kinetic Analysis (RPKA) technique pioneered by Blackmond. ${ }^{[23]}$ The reaction between $\mathrm{N}$-acyl imidazole 34 (75 $\mathrm{mM})$ and trifluoromethyl enone $2(50 \mathrm{mM})$ using (+)-BTM. HCl 5 (10 mM) in $\mathrm{CD}_{3} \mathrm{CN}$ at rt that forms dihydropyranone 11 in $71 \%$ yield, 85:15 dr and 95:5 er was chosen as standard as the concentrations of all fluorine containing species can be effectively monitored over time by in situ ${ }^{19} \mathrm{~F}$ NMR spectroscopy using $\alpha, \alpha, \alpha$-trifluorotoluene as an internal standard (Figure 1). The decreasing concentrations of both reactants and the formation of both diastereoisomers of product 11, as well as the concentration of $\mathrm{N}$-acyl ammonium 35, could be observed over a suitable reaction time.

The corresponding reaction profile obtained using free-base (+)-BTM 31 as the catalyst showed a slower initial rate of consumption of the reactants and no measurable formation of $\mathrm{N}$ acyl ammonium 35. ${ }^{[24]}$ This provides strong evidence of a beneficial "imidazolium effect" that promotes formation of $\mathrm{N}$-acyl ammonium 35 and increases the overall reaction rate.

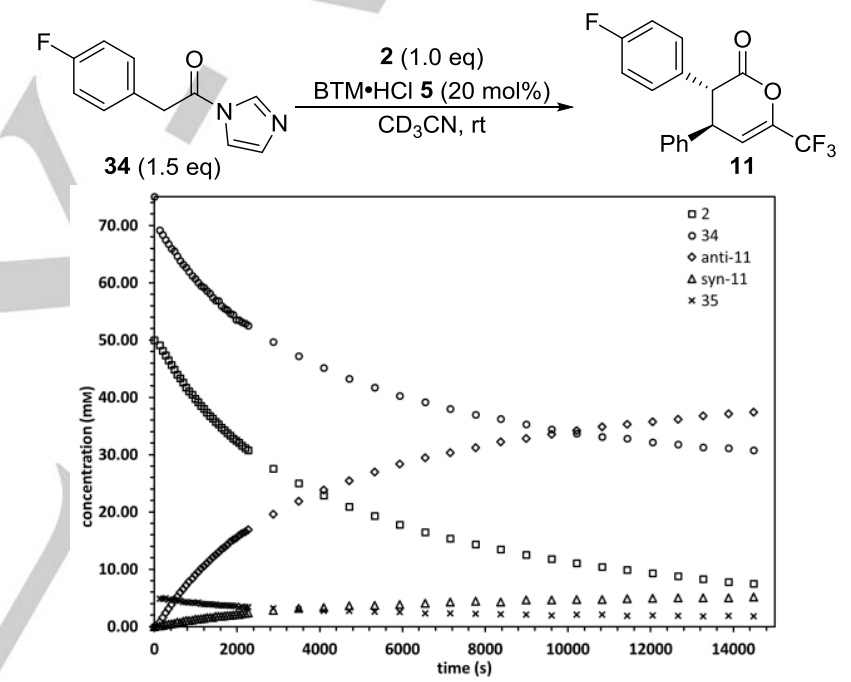

Figure 1. Reaction profile; initial conditions: 34 (75 mM), 2 (50 mM), (+)$\mathrm{BTM} \cdot \mathrm{HCl} 5(10 \mathrm{~mm})$ in $\mathrm{CD}_{3} \mathrm{CN}$.

The reaction order in (+)-BTM. $\mathrm{HCl} 5$ was assessed using the graphical normalized time scale method recently reported by Burés. ${ }^{[25]}$ Full reaction profiles at different catalyst concentrations were obtained and plotting the concentration of $\mathrm{N}$-acyl imidazole 34 against a normalized time scale, $\mathrm{t}[5]^{\mathrm{n}}$, where $\mathrm{n}$ represents the order with respect to catalyst, showed that $n=1$ (first-order) gave the best graphical overlay (Figure 2a). ${ }^{[26,27]}$ Next, a same excess experiment was performed in which two different starting concentrations of $\mathbf{3 4}$ were used, but with the same excess ([34][2] = $25 \mathrm{mM}$ ) with respect to enone 2 (Figure 2b). ${ }^{[26]}$ The time adjusted reaction profile ( $\square$ ), in which the starting concentrations of 2 are aligned, displays poor overlap with the standard profile (०). However, by adding the expected imidazole 33 (25 mM) byproduct the time-adjusted profile $(\Delta)$ displayed better visual correlation. ${ }^{[28]}$ This suggests that release of free imidazole 33 throughout the reaction inhibits the reaction rate.

The reaction orders with respect to both $\mathrm{N}$-acyl imidazole $\mathbf{3 4}$ and enone 2 were then assessed by means of a graphical rate 

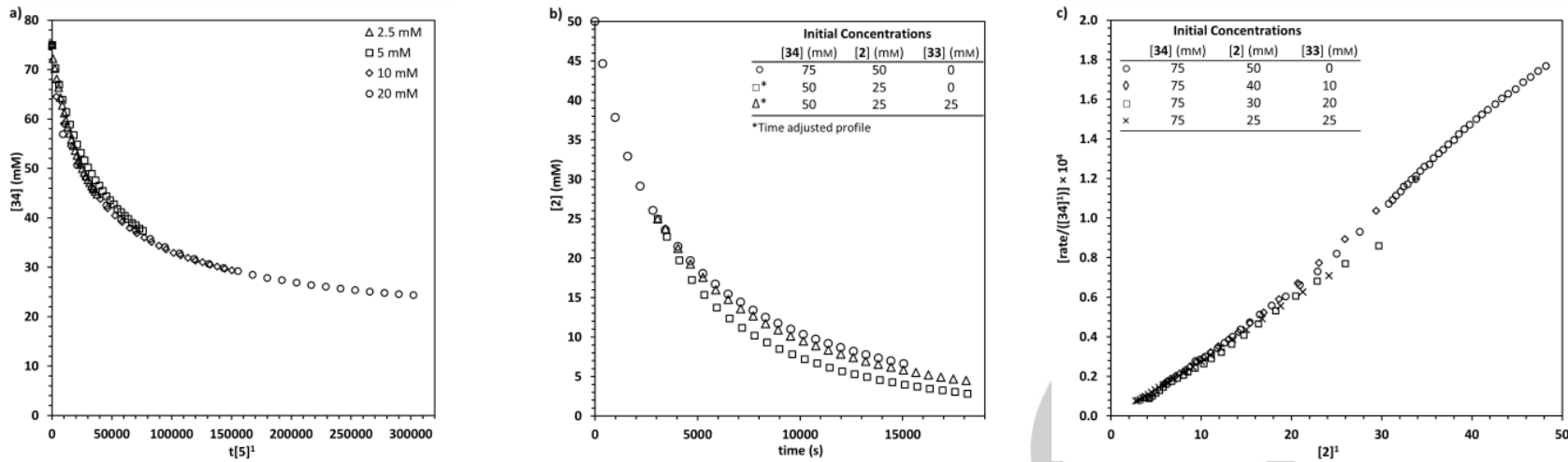

Figure 2. a) Determination of catalyst order using a time-normalized profile; initial conditions: $34(75 \mathrm{mM}), 2(50 \mathrm{mM}),(+)-\mathrm{BTM} \cdot \mathrm{HCl} 5$ (varied) in $\mathrm{CD}{ }_{3} \mathrm{CN}$. b) Same excess experiments with time adjusted profiles. c) Graphical rate equation obtained using varying excesses of 34 and 2 with (+)-BTM. $\mathrm{HCl} 5(10 \mathrm{mM})$ in $\mathrm{CD} \mathrm{C}_{3} \mathrm{CN}$.

equation by obtaining reaction profiles at different reaction excesses in the presence of added imidazole 33 (Figure 2c). A plot of rate/[34] ${ }^{\mathrm{x}}$ versus $[\mathbf{2}]^{\mathrm{y}}$, where $\mathrm{x}$ and $\mathrm{y}$ represent the respective reaction orders, showed good graphical overlap and linearity when both components are first order $(x=y=1) \cdot{ }^{[26]}$ The reaction kinetics show that the rate is positively dependent on the concentration of enone 2, indicating that Michael addition into 2 may be turnover-rate limiting. To further support this, an inverse secondary kinetic isotope effect $\left(k_{\mathrm{H}} / k_{\mathrm{D}}=0.75\right)$ was observed through independent initial rate measurements of the reactions using enone isotopologues 2 and 37-d (Scheme 3). These studies indicate that the mechanism of this base-free process is distinct to that of ammonium enolate generation from arylacetic acids under traditional basic conditions, where deprotonation is turnover-limiting and the reaction is zero order with respect to enone $2 .^{[14]}$

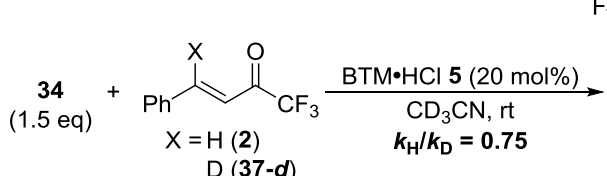

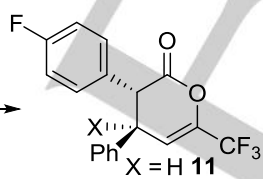

Scheme 3. Secondary kinetic isotope effect measurement.

Finally, the catalyst resting state was probed by using a fluorinated catalyst, (+)-F-BTM- $\mathrm{HCl}$, and tracking the concentrations of the catalyst-derived species. During the reaction, the concentration of the corresponding $\mathrm{N}$-acyl ammonium decreases over time, while the concentration of free (+)-F-BTM increases. ${ }^{[26]}$ This suggests that the overall process may follow a complex kinetic equation as a consequence of the catalyst having no definitive resting state. ${ }^{[29]}$ This is plausible given the observed equilibrium between (+)-BTM-HCl $\mathbf{5}, \mathrm{N}$-acyl imidazole 1 and $\mathrm{N}$-acyl ammonium 32, the position of which will vary as the concentration of imidazole $\mathbf{3 3}$ increases throughout the reaction.

The above evidence allows the following catalytic cycle to be proposed (Scheme 4). Initial equilibration between (+)BTM. $\mathrm{HCl} 5, \mathrm{~N}$-acyl imidazole 1 and $\mathrm{N}$-acyl ammonium 32 is likely to be facilitated by transient formation of $\mathrm{N}$-acyl imidazolium 36. The reaction displays a negative kinetic order in released imidazole $\mathbf{3 3}$ as its concentration affects the position of the initial equilibrium. Furthermore, as the reaction displays no definitive catalyst resting state the overall reaction kinetics are complex. Deprotonation of $\mathrm{N}$-acyl ammonium 32 using either imidazole $\mathbf{3 3}$ or another $\mathrm{N}$-acyl imidazole $\mathbf{1}$ forms (Z)-ammonium enolate 39, which can undergo turnover-limiting stereoselective Michael addition into enone 2. The conformation of $\mathbf{3 9}$ is thought to be stabilized by a non-bonding $n_{0}$ to $\sigma^{*}{ }_{c-s}$ interaction, ${ }^{[30]}$ allowing the stereoselective Michael addition to occur on the opposite face to the stereodirecting phenyl substituent on the isothiourea. Finally, lactonization releases the catalyst and forms the dihydropyranone product 4 .

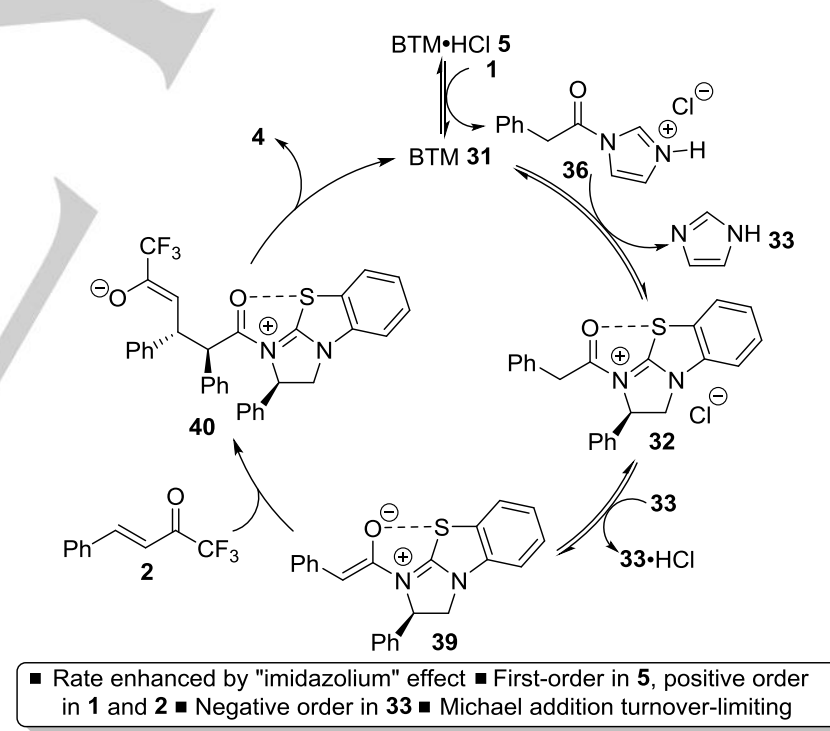

Scheme 4. Proposed reaction mechanism.

In conclusion, bench-stable $\mathrm{N}$-acyl imidazoles are ammonium enolate precursors under mild, base-free conditions in the presence of catalytic isothiourea hydrochloride salts. The ammonium enolates undergo highly stereoselective Michael addition-lactonization / lactamization processes in the presence of various $\alpha, \beta$-unsaturated Michael acceptors. Mechanistic studies have revealed the importance of the "imidazolium effect" to promote reactivity, which represents a new paradigm in ammonium enolate formation. The use of Reaction Progress Kinetic Analysis has allowed the complex reaction kinetics to be probed, identifying the Michael addition step as turnover-rate 
limiting and the imidazole by-product as a source of product inhibition. Further studies within this laboratory are focused on the development and mechanistic understanding of Lewis-base catalysed processes. ${ }^{[31]}$

\section{Acknowledgements}

We thank $\operatorname{Dr}$ Paul Dingwall for his insightful discussions regarding RPKA. We thank the European Research Council under the European Union's Seventh Framework Programme (FP7/2007-2013) ERC Grant Agreement no. 279850 (CMY, THW, JET). ADS thanks the Royal Society for a Wolfson Merit Award. We also thank the EPSRC UK National Mass Spectrometry Facility at Swansea University.

Keywords: $N$-Acyl imidazoles • Isothiourea catalysis • Michael addition $•$ Imidazolium effect $•$ Mechanistic study

[1] For reviews on the generation and use of ammonium enolates, see: a) S. France, D. J. Guerin, S. J. Miller, T. Lectka, Chem. Rev. 2003, 103, 2985-3012; b) M. J. Gaunt, C. C. C. Johansson, Chem. Rev. 2007, 107 5596-5605; c) D. H. Paull, A. Weatherwax, T. Lectka, Tetrahedron 2009 65, 6771-6803; d) L. C. Morrill, A. D. Smith, Chem. Soc. Rev. 2014, 43 6214-6226.

[2] For seminal examples, see: a) R. Tennyson, D. Romo, J. Org. Chem. 2000, 65, 7248-7252; b) A. E. Taggi, A. M. Hafez, H. Wack, B. Young D. Ferraris, T. Lectka, J. Am. Chem. Soc. 2002, 124, 6626-6635; c) C Zhu, X. Shen, S. G. Nelson, J. Am. Chem. Soc. 2004, 126, 5352-5353.

[3] L. C. Morrill, L. A. Ledingham, J.-P. Couturier, J. Bickel, A. D. Harper, C. Fallan, A. D. Smith, Org. Biomol. Chem. 2014, 12, 624-636.

[4] a) T. H. West, D. S. B. Daniels, A. M. Z. Slawin, A. D. Smith, J. Am Chem. Soc. 2014, 136, 4476-4479; b) K. J. Schwarz, J. L. Amos, J. C Klein, D. T. Do, T. N. Snaddon, J. Am. Chem. Soc. 2016, 138, 52145217.

[5] For seminal examples, see: a) G. S. Cortez, R. L. Tennyson, D. Romo, J. Am. Chem. Soc. 2001, 123, 7945-7946; b) S. H. Oh, G. S. Cortez, D. Romo, J. Org. Chem. 2005, 70, 2835-2838; c) H. Henry-Riyad, C. Lee, V. C. Purohit, D. Romo, Org. Lett. 2006, 8, 4363-4366; d) C. A. Leverett, V. C. Purohit, D. Romo, Angew. Chem. Int. Ed. 2010, 49, 9479-9483; Angew. Chem. 2010, 122, 9669-9673; e) D. Belmessieri, L. C. Morrill, C. Simal, A. M. Z. Slawin, A. D. Smith, J. Am. Chem. Soc. 2011, 133, 2714-2720.

[6] For seminal work, see: a) R. Wolfenden, W. P. Jencks, J. Am. Chem. Soc. 1961, 83, 4390-4393; b) W. P. Jencks, D. G. Oakenfull, K. Salvesen, J. Am. Chem. Soc. 1971, 93, 188-194.

[7] J. A. Grzyb, M. Shen, C. Yoshina-Ishii, W. Chi, R. S. Brown, R. A. Batey, Tetrahedron 2005, 61, 7153-7175.

[8] E. K. Woodman, J. G. K. Chaffey, P. A. Hopes, D. R. J. Hose, J. P. Gilday, Org. Proc. Res. Dev. 2009, 13, 106-113.

[9] S. T. Heller, T. Fu, R. Sarpong, Org. Lett. 2012, 14, 1970-1973.

[10] DMAP salts effectively catalyse acylations via $\mathrm{N}$-acyl ammonium intermediate formation under base-free conditions, see: a) A. Sakakura, K. Kawajiri, T. Ohkubo, Y. Kosugi, K. Ishihara, J. Am. Chem. Soc. 2007 129, 14775-14779; b) D. Vuluga, J. Legros, B. Crousse, D. BonnetDelpon, Chem. Eur. J. 2010, 16, 1776-1779; c) Z. Liu, Q. Ma, Y. Liu, Q. Wang, Org. Lett. 2014, 16, 236-239.

[11] a) A. Lee, A. Younai, C. K. Price, J. Izquierdo, R. K. Mishra, K. A. Scheidt, J. Am. Chem. Soc. 2014, 136, 10589-10592; b) A. Lee, K. A Scheidt, Chem. Commun. 2015, 51, 3407-3410.

[12] Enders has reported the use of $\alpha, \beta$-unsaturated $N$-acyltriazoles as $\alpha, \beta$ unsaturated acyl azolium precursors for annulations with 1,3 dicarbonyls under basic conditions, see: Q. Ni, J. Xiong, X. Song, G. Raabe, D. Enders, Chem. Commun. 2015, 51, 14628-14631.

[13] For reviews on isothioureas as Lewis base catalysts, see: a) J. E. Taylor, S. D. Bull, J. M. J. Williams, Chem. Soc. Rev. 2012, 41, 2109 2121; b) J. Merad, J.-M. Pons, O. Chuzel, C. Bressy, Eur. J. Org. Chem. 2016, doi:10.1002/ejoc.201600399; c) L. C. Morrill, A. D. Smith, Chem. Soc. Rev. 2014, 43, 6214-6226.

[14] For the corresponding reaction under basic conditions starting from arylacetic acids, see: L. C. Morrill, J. Douglas, T. Lebl, A. M. Z. Slawin, D. J. Fox, A. D. Smith, Chem. Sci. 2013, 4, 4146-4155

[15] A control experiment in the absence of tetramisole $\mathrm{HCl} 3$ led to the formation of $( \pm)-4$ in $28 \%$ yield, suggesting a base-promoted background process is responsible for the observed reactivity.

[16] The absolute and relative configuration of the product was confirmed by comparison of its specific rotation and spectral data with the literature, ref 14.

[17] For a complete reaction optimization table, see the Supporting Information.

[18] The absolute and relative configuration of the product was confirmed by comparison of its specific rotation and spectral data with the literature: P.-P. Yeh, D. S. B. Daniels, C. Fallan, E. Gould, C. Simal, J. E. Taylor A. M. Z. Slawin, A. D. Smith, Org. Biomol. Chem. 2015, 13, 2177-2191.

[19] The absolute and relative configuration of the product were assigned by analogy to the other series reported.

[20] The same equilibrium position was obtained starting from a mixture of $\mathrm{N}$-acyl ammonium 32, obtained from the reaction of (+)-BTM 5 with phenacyl chloride, and imidazole 33.

[21] See the Supporting Information for more details.

[22] The observed cross-over may occur via an intermediate $N, N$-diacyl imidazolium species, although no direct evidence for this could be obtained. Alternatively, the in situ formation of a ketene intermediate is another possible pathway.

[23] For reviews on this technique, see: a) D. G. Blackmond, Angew. Chem Int. Ed. 2005, 44, 4302-4320; Angew. Chem. 2005, 117, 4374-4393; b) D. G. Blackmond, J. Am. Chem. Soc. 2015, 137, 10852-10866.

[24] Synthetically, this gave product 11 in 70\% NMR yield, 86:14 dr and $81: 19$ er.

[25] J. Burés, Angew. Chem. Int. Ed. 2016, 55, 2028-2031.

[26] See the Supporting Information for full reaction profiles and analysis.

[27] The same order in catalyst could also be obtained by initial rate analysis. See the Supporting Information for more details.

[28] The remaining minor discrepancy between the time-adjusted sameexcess profile containing imidazole $\mathbf{3} 3$ and the original data may be due to either experimental error or minimal catalyst deactivation.

[29] For other examples of complex reaction kinetics due at least in part to no definitive catalyst resting state, see: a) S. Y. Lee, J. M. Murphy, A Ukai, G. C. Fu, J. Am. Chem. Soc. 2012, 134, 15149-15153; b) L. Mesas-Sánchez, P. Dinér, Chem. Eur. J. 2015, 21, 5623-5631.

[30] a) V. B. Birman, X. Li, Z. Han, Org. Lett. 2007, 9, 37-40; b) P. Liu, X Yang, V. B. Birman, K. N. Houk, Org. Lett. 2012, 14, 3288-3291.

[31] The research data underpinning this publication can be found at DOI: http://dx.doi.org/10.17630/346a5fe8-a636-46e8-9933-71db82f0083a 


\section{Entry for the Table of Contents}

\section{COMMUNICATION}

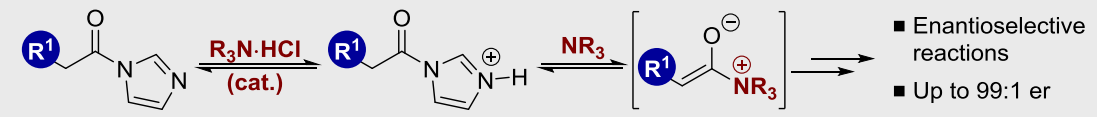

- Base-free enolate formation - "Imidazolium effect" promoted reactions - Mechanistic study

Drop the Base: $\mathrm{N}$-Acyl imidazoles act as ammonium enolate precursors in the presence of catalytic isothiourea hydrochloride salts in the absence of base. Subsequent reactions with various Michael acceptors proceed with high stereoselectivity. Mechanistic investigations have revealed the importance of the "imidazolium effect" during enolate formation and highlight key differences with traditional base-mediated processes.
Claire M. Young, Daniel G. Stark, Thomas H. West, James E. Taylor, Andrew D. Smith*

Page No. - Page No.

Exploiting the Imidazolium Effect in Base-free Ammonium Enolate Generation: Synthetic and Mechanistic Studies 